\title{
Markedly Reduced Activity of Mutant Calcium-sensing Receptor with an Inserted Alu Element from a Kindred with Familial Hypocalciuric Hypercalcemia and Neonatal Severe Hyperparathyroidism
}

\author{
Mei Bai, ${ }^{\star}$ Natasa Janicic, ${ }^{\ddagger}$ Sunita Trivedi, ${ }^{\star}$ Stephen J. Quinn, ${ }^{\star}$ David E.C. Cole, ${ }^{\S}$ Edward M. Brown, ${ }^{\star}$ and Geoffrey N. Hendy ${ }^{\ddagger}$ \\ *Endocrine-Hypertension Division, Department of Medicine, Brigham and Women's Hospital, Harvard Medical School, Boston, \\ Massachusetts 02115; ${ }^{\ddagger}$ Departments of Medicine and Physiology, McGill University and Royal Victoria Hospital, Montreal, Quebec H3A \\ 1A1, Canada; and ${ }^{\S}$ Department of Clinical Biochemistry, Department of Medicine, and Department of Paediatrics (Genetics), University \\ of Toronto and Banting Institute, Toronto, Ontario, M5G IL5 Canada
}

\begin{abstract}
Missense mutations have been identified in the coding region of the extracellular calcium-sensing receptor (CASR) gene and cause human autosomal dominant hypo- and hypercalcemic disorders. The functional effects of several of these mutations have been characterized in either Xenopus laevis oocytes or in human embryonic kidney (HEK293) cells. All of the mutations that have been examined to date, however, cause single putative amino acid substitutions. In this report, we studied a mutant CASR with an Alu-repetitive element inserted at codon 876 , which was identified in affected members of families with the hypercalcemic disorders, familial hypocalciuric hypercalcemia (FHH) and neonatal severe hyperparathyroidism (NSHPT), to understand how this insertion affects CASR function. After cloning of the Alu-repetitive element into the wild-type CASR cDNA, we transiently expressed the mutant receptor in HEK293 cells. Expression of mutant and wild-type receptors was assessed by Western analysis, and the effects of the mutation on extracellular calcium $\left(\mathrm{Ca}^{2+}{ }_{0}\right)$ and gadolinium $\left(\mathrm{Gd}^{3+}{ }_{0}\right)$ elicited increases in the cytosolic calcium concentration $\left(\mathrm{Ca}^{2+}{ }_{\mathrm{i}}\right)$ were examined in fura-2-loaded cells using dual wavelength fluorimetry. The insertion resulted in truncated receptor species that had molecular masses some $30 \mathrm{kD}$ less than that of the wild-type CASR and exhibited no $\mathrm{Ca}^{2+}{ }_{\mathrm{i}}$ responses to either $\mathrm{Ca}^{2+}{ }_{0}$ or $\mathrm{Gd}^{3+}{ }_{0}$. A similar result was observed with a mutated CASR truncated at residue 876. However, the Alu mutant receptor had no impact on the function of the coexpressed wild-type receptor. Interestingly, the Alu mutant receptor demonstrated decreased cell surface expression relative to the wild-type receptor, whereas the CASR (A877stop) mutant exhibited increased cell surface expression. Thus, like the missense mutations that have been characterized to date in families with $\mathrm{FHH}$, the Alu insertion in this family is a loss-of-function mutation that produces hypercalcemia by
\end{abstract}

Address correspondence to Geoffrey N. Hendy, Calcium Research Laboratory, Rm. H4.67, Royal Victoria Hospital, 687 Pine Avenue West, Montréal, Québec, H3A 1A1 Canada. Phone: 514-843-1632; FAX: 514-843-1712.

Received for publication 10 September 1996 and accepted in revised form 3 February 1997.

J. Clin. Invest.

(C) The American Society for Clinical Investigation, Inc.

0021-9738/97/04/1917/09 \$2.00

Volume 99, Number 8, April 1997, 1917-1925 reducing the number of normally functional CASRs on the surface of parathyroid and kidney cells. In vitro transcription of exon 7 of the CASR containing the Alu sequence yielded the full-length mutant product and an additional shorter product that was truncated due to stalling of the polymerase at the poly(T) tract. In vitro translation of the mutant transcript yielded three truncated protein products representing termination in all three reading frames at stop codons within the Alu insertion. Thus sequences within the Alu contribute to slippage or frameshift mutagenesis during transcription and/or translation. (J. Clin. Invest. 1997. 99: 1917-1925.) Key words: hypercalcemia • hyperparathyroidism - Alu repeat • transcription • translation

\section{Introduction}

Familial hypocalciuric hypercalcemia $\left([\mathrm{FHH}]^{1}\right.$ also known as familial benign hypercalcemia) is an autosomal dominant condition characterized by modest elevation in serum calcium concentration, relative hypocalciuria, and inappropriately normal (i.e., nonsuppressed) parathyroid hormone (PTH) levels (1-3). However, affected individuals exhibit virtually none of the usual morbidity associated with hypercalcemia. Neonatal severe hyperparathyroidism ([NSHPT] also termed neonatal familial primary hyperparathyroidism), on the other hand, is a disorder characterized by marked elevation in serum calcium and PTH levels, skeletal demineralization, and parathyroid cellular hyperplasia that can be lethal without parathyroidectomy $(4,5)$. Despite the disparate clinical features of these conditions, the coexistence of NSHPT and FHH in some families suggested a relationship between these two disorders (6-8). Identification of inactivating mutations in the extracellular calcium $\left(\mathrm{Ca}^{2+}{ }_{\mathrm{o}}\right)$-sensing receptor (CASR) $(9,10)$ located in chromosome region 3q13.3-21 (11), revealed molecular interrelationships between FHH and NSHPT $(12,13)$. That is, individuals with FHH are heterozygous, and some cases of NSHPT are homozygous for such mutations (also see references 14-17).

The wild-type human CASR is a G protein-coupled receptor predicted to be 1,078 amino acids in length. Stimulation of the receptor by polycationic agonists, such as $\mathrm{Ca}^{2+}{ }_{0}, \mathrm{Mg}^{2+}{ }_{0}$, and $\mathrm{Gd}^{3+}$ o, activates phospholipase $\mathrm{C}$ with resultant increases in inositol phosphates and the cytosolic calcium concentration $\left(\mathrm{Ca}^{2+}{ }_{\mathrm{i}}\right)$. The CASR was found to be most abundant in parathy-

1. Abbreviations used in this paper: $\mathrm{Ca}^{2+}$, intracellular calcium; $\mathrm{Ca}^{2+}{ }_{0}$, extracellular calcium; CASR, calcium-sensing receptor; $\mathrm{FHH}$, familial hypocalciuric hypercalcemia; NSHPT, neonatal severe (primary) hyperparathyroidism; PTT, protein truncation test. 
roid gland, which secretes high levels of PTH in response to decreased levels of $\mathrm{Ca}^{2+}{ }_{o}$ or, conversely, less PTH when exposed to increased levels of $\mathrm{Ca}^{2+}{ }_{0}$. The primary actions of PTH on kidney and bone are to raise serum calcium levels by increasing reabsorption of calcium in the former and resorption of calcium and phosphate in the latter, thereby elevating $\mathrm{Ca}^{2+}{ }_{\mathrm{o}}$ (18). The identification of mutations in the CASR in FHH and NSHPT strongly supports the concept that the receptor is a key element in mediating the physiological responses of the parathyroid gland to alterations in $\mathrm{Ca}^{2+}$. The receptor was also localized in kidney with a lower abundance. It has been hypothesized that the CASR acts as an antagonist to PTH action on renal $\mathrm{Ca}^{2+}$ handling (19). That is, activation of the receptor directly reduces calcium reabsorption in the distal tubule. When the activity of the receptor is reduced by inactivating mutations, in turn, a higher than normal level of $\mathrm{Ca}^{2+}{ }_{\mathrm{o}}$ is required to achieve a given degree of suppression of PTH release from the parathyroid gland and enhancement of calcium excretion by the kidney, consistent with the phenotype of "resistance" to $\mathrm{Ca}^{2+}{ }_{\mathrm{o}}$ observed in FHH and NSHPT.

Recent functional characterization of some mutated CASRs that had been identified in patients with FHH or NSHPT revealed that mutations could interfere with $(a)$ posttranslational modification of the CASR by $N$-glycosylation with more complex carbohydrates; $(b)$ sensitivity of the CASR to ligands;
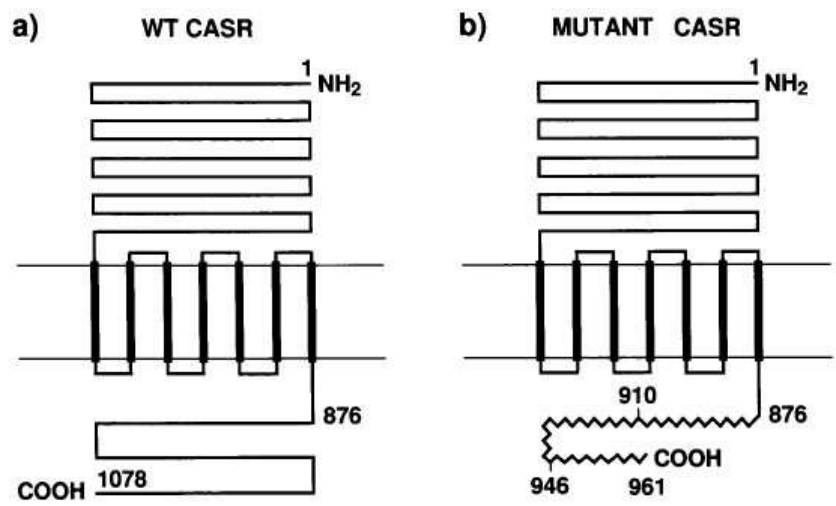

c)

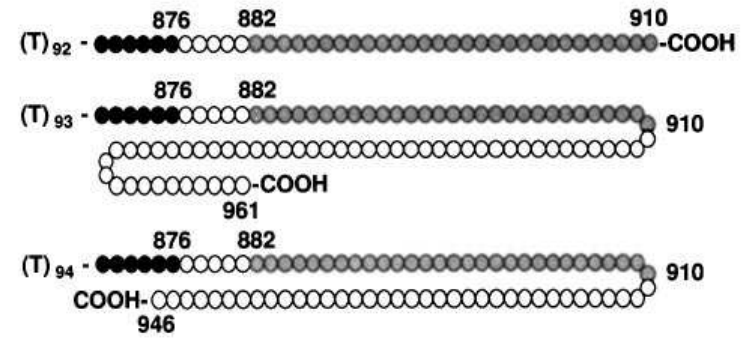

- Wild type CASR sequence

O Mutant CASR sequence

O Phenylalanine

Figure 1. Predicted structural consequences of the Alu mutation in the CASR. (a) The wild-type CASR has 1,078 amino acids. (b) The mutant CASR is a truncated protein of between 910 and 961 amino acids. (c) The normal CASR protein sequence stops at amino acid 876 and is followed by the sequence Gln-Leu-Thr-Leu-Ser and 29 Phe residues encoded by the poly(U) tract. Then depending on the reading frame, the mutant CASR will terminate at amino acid 910, 946, or 961. The two larger predicted mutant proteins differ in size from the smallest by $\sim 4$ and $\sim 6 \mathrm{kD}$, respectively. and/or $(c)$ activation of associated $\mathrm{G}$ protein $(20,21)$. We recently documented the insertion of a complete Alu repetitive element at codon 876 in the intracellular domain of the CASR in both FHH and NSHPT (17). The Alu repeat is in the opposite orientation to the CASR gene and contains an exceptionally long poly(A/T) tract of between 92 and $94 \mathrm{bp}$. The insertion is predicted to yield a truncated protein of 910-961 amino acids in length, with loss of the normal CASR sequence of 877 1078 amino acids (see Fig. 1). The first 876 amino acids of the CASR would be tailed by the unrelated sequence, QLTLS, and a stretch of 29 phenylalanine residues encoded by the poly $(\mathrm{U})$ tract. Then depending upon the reading frame, the mutant CASR protein terminates at either amino acid 910, 946, or 961.

In this report, we have expressed the full-length receptor containing the Alu insertion in HEK293 cells and determined its $(a)$ pattern of protein expression, $(b)$ responses to CASR agonists (e.g., $\mathrm{Ca}^{2+}{ }_{\mathrm{o}}$ and $\mathrm{Gd}^{3+}{ }_{\mathrm{o}}$ ), and (c) functional impact on the coexpressed wild-type receptor (to mimic the heterozygous state of $\mathrm{FHH}$ ). To evaluate the effect of the Alu insertion on transcription and translation in vitro, we used a modified protein truncation test (PTT).

\section{Methods}

Clinical and genetic studies. Consent was obtained from all participants or their guardians in accordance with local institutional guidelines. The three families $(\mathrm{D}, \mathrm{Qu}$, and $\mathrm{S})$ with affected $\mathrm{FHH}$ and NSHPT members harboring the Alu insertion have been described previously $(5,13,17,22,23)$. Measurement of serum total calcium concentration was carried out by colorimetric assay, and measurement of serum ionized calcium was performed using a Nova 7 Analyzer (Nova Biomedical, Waltham, MA). DNA was extracted from peripheral lymphocytes as described previously (24). For one affected member of each family the presence of the Alu insertion in exon 7 of the CASR was demonstrated by PCR analysis of genomic DNA as described previously (17), and in all other family members the presence of the mutation was tested for by Southern blot analysis of AvaII-digested genomic DNA using a $\left[{ }^{32} \mathrm{P}\right]$-labeled CASR-exon 7 probe.

In vitro transcription and translation of partial CASR coding region containing the Alu insertion. Nucleotides +1804 to +3333 encoding the CASR mRNA ( +1 is the first nucleotide of the AUG initiation codon and +3237 is the last nucleotide of the TAA stop codon) were PCR-amplified from genomic DNA from either unaffected or NSHPT individuals using the primers shown in Table I. Forward primer, PTT-F(T7), which was used if the PCR product was directly transcribed without subcloning, was modified at its $5^{\prime}$ end by addition of a T7 promoter and consensus eukaryotic translation initiation sequence. Forward primer, PTT-F, was used if the PCR product was subcloned first, before transcription, and, in all cases, reverse primer, PTT-R, was used. $500 \mathrm{ng}$ genomic DNA were used as template in $50-\mu \mathrm{l}$ reactions containing PCR buffer $(10 \mathrm{mM}$ Tris- $\mathrm{HCl}, \mathrm{pH} 8.3,50 \mathrm{mM}$ $\mathrm{KCl}, 1.5 \mathrm{mM} \mathrm{MgCl}, 0.001 \%$ [wt/vol] gelatin), $200 \mu \mathrm{M}$ of each deoxynucleotide, $50 \mathrm{pmol}$ of each primer, and 0.5 units Taq polymerase (Perkin-Elmer Cetus Corp., Norwalk, CT). PCR conditions were as follows: $5 \mathrm{~min}$ at $98^{\circ} \mathrm{C}$, followed by 30 cycles of $45 \mathrm{~s}$ at $94^{\circ} \mathrm{C}, 2.5 \mathrm{~min}$ at $62^{\circ} \mathrm{C}, 1 \mathrm{~min}$ at $72^{\circ} \mathrm{C}$, and a final elongation step at $72^{\circ} \mathrm{C}$ for $10 \mathrm{~min}$, using the GeneAmp PCR System Thermocycler 9600 (Perkin-Elmer Cetus Corp.). A deletion mutant was created lacking the long poly(A/T) tract in the Alu repetitive sequence by generating overlapping PCR products using primers PTT-F and DEL-R, and DEL-F and PTT-R (Table I). The final recombinant was generated by amplifying the two products with PTT-F and PTT-R. PCR conditions were as described above. The PCR products were subcloned into the pCR2.1 TA cloning vector (Invitrogen Corp., San Diego, CA) and selected for an ap- 
Table I.

No.

Sequence

(A) Primers used to generate constructs for in vitro transcription/translation assay

$\begin{array}{lc}\text { PTT-F(T7)* } & \text { 5'-GCTAATACGACTCACTATAGGAACAGACCACCATGGAGATCGAGTTTCTGTCGTGG-3' } \\ \text { PTT-F } & \text { 5'-GAGATCGAGTTTCTGTCGTGG-3' } \\ \text { PTT-R } & \text { 5'-TCTTCCTCAGAGGAAAGGAGTCTGG-3' } \\ \text { DEL-F } & \text { 5'-AGCACGCAGCTCACGCTTGACGGAGTCTCGCTTCGTCGC-3' } \\ \text { DEL-R } & \text { 5'-AAGCGTGAGCTGCGTGCTGCAACGCACCTCTTCGATGGTGTT-3' } \\ \text { B) Primer used to construct the CASR (A876stop) mutant } & \text { 5'-GAAAGCGTGAGCTTAGGTGCTGCAACG-3' } \\ \text { MUT1* } & \text { 5' }{ }^{\prime} \text { - Primers used to insert a FLAG epitope into the CASR } \\ \text { M13 } & \text { 5'-GTAAAACGACGGCCAGTG-3' } \\ \text { FLAG-R } & \text { 5'-CTTGTCATCGTCATCCTTGTAGTCCACAGGTAAAGGTCCT-3' } \\ \text { FLAG-F } & \text { 5'-GACTACAAGGATGACGATGACAAGACCTTTCTGAGAGGTCACG-3' } \\ \text { T3 } & \text { 5'-AATTAACCCTCACTAAAGGG-3' }\end{array}$

*T7 promoter and eukaryotic initiation sequence is bolded in PTT-F(T7). Complementary sequence to the TAA stop codon is bolded in MUT1.

propriate orientation downstream of the $\mathrm{T} 7$ promoter. The plasmid DNAs were linearized at the $3^{\prime}$ end of the coding sequence by XbaI digestion. Sense strand RNAs were generated with T7 RNA polymerase (Promega Corp., Madison, WI) as described by Melton et al. (25). The RNA concentrations were determined by $\mathrm{OD}_{260}$. In vitro transcribed products were analyzed on a denaturing formaldehyde gel in $0.1 \mathrm{M}$ Mops ( $\mathrm{pH} 7.0$ ) running buffer. $1 \mu \mathrm{g}$ of each RNA was used as a template for protein synthesis in a rabbit reticulocyte lysate in vitro translation system (Promega Corp.) in the presence of $\left[{ }^{3} \mathrm{H}\right] \mathrm{leu}-$ cine (Amersham Corp., Arlington Heights, IL) at $30^{\circ} \mathrm{C}$ for $1 \mathrm{~h}$. The translated proteins were analyzed using SDS-PAGE $(12.5 \%$ polyacrylamide). The gel was fixed in an aqueous solution with $19 \%$ acetic acid and 29\% methanol for 60 min, soaked in $\mathrm{En}^{3} \mathrm{Hance}$ (NEN Research Products, Boston, MA) for $30 \mathrm{~min}$, dried at $80^{\circ} \mathrm{C}$ for $2 \mathrm{~h}$, and autoradiographed.

Cloning of the Alu insert into the full-length wild-type receptor. A PCR product with the Alu insertion at amino acid 876 was obtained using primers 7BF and 7BR as described (17) and cloned into the pCRII TA cloning vector (Invitrogen Corp.). The plasmid was doubly digested with SphI and BamHI, and its B-fragment was cloned into cassette VI of the reconstructed human CASR cDNA (20). Then the cassette VI carrying the Alu insertion was doubly digested with $\mathrm{XhoI}$ and $\mathrm{XbaI}$ and cloned into the wild-type reconstructed receptor in pcDNA3 (20).

Site-directed mutagenesis. Site-directed mutagenesis to produce a receptor truncated at amino acid position 876 was performed using the approach described by Kunkel $(20,26)$. The dut- 1 ung- 1 strain of Escherichia coli, CJ236, was transformed with mutagenesis cassette 6 as described by Bai et al. (20). Uracil-containing, single stranded (ss) DNA was produced by infecting the cells with the helper phage, VCSM13. The ssDNA was then annealed to a mutagenesis primer (MUT1; see Table I) that contained the desired nucleotide change encoding a single point mutation (in this case introduction of a stop codon) flanked on both sides by wild-type sequence. The primer was then extended around the entire ssDNA and ligated to generate closed circular heteroduplex DNA. DH5 $\alpha$ competent cells were transformed with the heteroduplex DNA, and incorporation of the desired mutation was confirmed by sequencing the entire cassette.

Transient expression of the wild-type receptor and the mutated receptor carrying the Alu insertion in HEK293 cells. The DNA for transfection was prepared using the Midi Plasmid Kit (Qiagen Inc., Chatsworth, CA), and Lipofectamine (Gibco-BRL, Gaithersburg, MD) was used as a DNA carrier for transfection (27). The HEK293 cells used for transient transfection were provided by NPS Pharmaceuticals, Inc. (Salt Lake City, UT) and were cultured in DMEM (Gibco-BRL) with $10 \%$ FBS (Hyclone, Logan, VT). The DNA-liposome complex was prepared by mixing DNA and lipofectamine in Opti-MEM I reduced serum medium (Gibco-BRL) and incubating the mixture at room temperature for $30 \mathrm{~min}$. The DNA-lipofectamine mixture was then diluted with Opti-MEM I reduced serum medium and added to $90 \%$ confluent HEK293 cells plated on $13.5 \times 20.1-\mathrm{mm}$ glass cover slips using 0.625 or $2.5 \mu \mathrm{g}$ of DNA (for measurement of $\mathrm{Ca}^{2+}{ }_{i}$ ) or in 100-mm petri dishes using 3.75 or $15 \mu \mathrm{g}$ of DNA (for obtaining crude membrane protein for Western analysis). After $5 \mathrm{~h}$ incubation at $37^{\circ} \mathrm{C}$, equivalent amounts of Opti-MEM I reduced serum medium with $20 \%$ FBS were added to the medium overlying the transfected cells, and the latter was replaced with fresh DMEM with $10 \%$ FBS at $24 \mathrm{~h}$ after the transfection. The expressed CASR protein was assayed $48 \mathrm{~h}$ after the start of transfection (essentially identical $\mathrm{Ca}^{2+}{ }_{\mathrm{i}}$ doseresponse curves were obtained when either 0.625 or $2.5 \mu \mathrm{g}$ of DNA were transfected [reference 20]). To perform coexpression of wildtype and mutant receptors, $0.625 \mu \mathrm{g}$ each of wild-type and the mutant receptor cDNAs were mixed and used to transfect HEK293 cells as described above.

Tunicamycin treatment of transiently transfected HEK293 cells. Tunicamycin $(5 \mu \mathrm{g} / \mathrm{ml})$ (Boehringer-Mannhein Biochemicals, Indianapolis, IN) was added to HEK293 cells $5 \mathrm{~h}$ after transfection with the mutant receptor to block $N$-glycosylation of the newly synthesized receptor protein (28). The cells were then incubated for $48 \mathrm{~h}$ before harvesting of plasma membranes for Western analysis of the CASR as described below.

Crude plasma membrane preparation. Crude plasma membranes were isolated from HEK293 cells transiently transfected with $\mathrm{rHu}-$ PCaR4.0 (10) or the mutant receptor by differential speed centrifugation as described by Sun et al. (29). Confluent cultured cells in $100-\mathrm{mm}$ culture plates were rinsed twice with PBS and treated with $0.02 \%$ EDTA in PBS at $37^{\circ} \mathrm{C}$ for $5 \mathrm{~min}$. The detached cells were pelleted and resuspended in $300 \mu \mathrm{l}$ of homogenization buffer: $50 \mathrm{mM}$ Tris$\mathrm{HCl}, \mathrm{pH} 7.4$, containing $0.32 \mathrm{M}$ sucrose, $1 \mathrm{mM}$ EDTA, and protease inhibitors (including $83 \mu \mathrm{g} / \mathrm{ml}$ aprotonin, $30 \mu \mathrm{g} / \mathrm{ml}$ leupeptin, $1 \mu \mathrm{g} / \mathrm{ml}$ pefabloc, $50 \mu \mathrm{g} / \mathrm{ml}$ calpain inhibitor, $50 \mu \mathrm{g} / \mathrm{ml}$ bestatin, $5 \mu \mathrm{g} / \mathrm{ml}$ pepstatin, and $1 \mathrm{mM}$ EDTA). Then the cells were homogenized with 15 strokes of a motor-driven Teflon pestle in a tightly fitting glass tube. The homogenate was sedimented at $18,800 \mathrm{~g}$ for $20 \mathrm{~min}$ to remove nuclei and mitochondria. The supernatant was subsequently sedimented at 43,500 $\mathrm{g}$ for $20 \mathrm{~min}$ to pellet the plasma membranes, and the resultant pellet was solubilized with $1 \%$ Triton X-100. All steps were carried out at $4^{\circ} \mathrm{C}$.

Western analysis of plasma membrane proteins. After determination of the protein concentration in the crude plasma membrane 
preparations using the Pierce BCA protein assay (Pierce, Rockford, IL), an appropriate amount of membrane protein (4 $\mu \mathrm{g})$ was subjected to SDS-PAGE (30) using a linear gradient of polyacrylamide $(4-12 \%)$. The proteins on the gel were subsequently electrotransferred to a nitrocellulose membrane. After blocking with 5\% milk, the blot was incubated either with an antibody (4641; kindly provided by Drs. Forrest Fuller and Richel Simin, NPS Pharmaceuticals, Inc., Salt Lake City, UT), which is specific for the CASR (20), or the antiFLAG M2 Monoclonal antibody. The CASR protein was detected using a peroxidase-coupled secondary antibody with an ECL system (Amersham Corp.).

Measurement of $\mathrm{Ca}^{2+}{ }_{i}$ by fluorimetry in cell populations. Coverslips coated with HEK293 cells that had been transfected with wildtype and/or mutant CASR cDNAs were loaded for $2 \mathrm{~h}$ at room temperature with fura-2/AM in $20 \mathrm{mM}$ Hepes, $\mathrm{pH} 7.4$, containing $125 \mathrm{mM}$ $\mathrm{NaCl}, 4 \mathrm{mM} \mathrm{KCl}, 0.5 \mathrm{mM} \mathrm{CaCl}_{2}, 0.5 \mathrm{mM} \mathrm{MgCl}, 0.1 \%$ dextrose and $0.1 \% \mathrm{BSA}$ ) at $37^{\circ} \mathrm{C}$ for $20 \mathrm{~min}$. The coverslips were then placed diagonally in a thermostatted quartz cuvette containing standard medium, using a modification of techniques employed previously (31). CASR agonists were added to give the desired final concentrations. Excitation monochrometers were centered at 340 and $380 \mathrm{~nm}$ with emission light collected at $510 \pm 40 \mathrm{~nm}$ through a wide-band emission filter. The $340 / 380$ excitation ratio of emitted light was used to calculate $\mathrm{Ca}^{2+}{ }_{i}$ as described previously (31). Addition of $\mathrm{Ca}^{2+}{ }_{0}$ with stepwise $1 \mathrm{mM}$ increments was used to characterize the wild-type receptor. Increments of $5 \mathrm{mM}$ were used for the mutant receptors.

Statistics. The mean $\mathrm{EC}_{50}$ (the effective concentration of agonist giving one half of the maximal response) for the wild-type or mutant receptor in response to increasing concentrations of $\mathrm{Ca}^{2+}{ }_{\mathrm{o}}$ or $\mathrm{Gd}^{3+}{ }_{\mathrm{o}}$ was calculated from the $\mathrm{EC}_{50}$ 's for all of the individual experiments and is expressed with the standard error of the mean (SEM) as the index of dispersion. Comparison of the $\mathrm{EC}_{50}$ 's was performed using analysis of variance (32) or Duncan's multiple comparison test (33). A $P$ value of $<0.05$ was taken to indicate a statistically significant difference.

Insertion of a FLAG epitope into the extracellular domain of the receptor between D371 and T372. A DNA fragment in cassette 3 (20) which precedes the insertion position was amplified using the primer pair, M13 (20) and FLAG-R (Table I), and a fragment following the insertion position was amplified using the primer pair FLAG-F and T3 (Table I). The two PCR products were gel-purified, mixed with $1 \mu \mathrm{l}$ of $10 \mathrm{mM}$ dNTP, $5 \mu \mathrm{l}$ of $10 \times$ reaction buffer (Promega Corp.), $3.75 \mu \mathrm{l}$ of $25 \mathrm{mM} \mathrm{MgCl} 2$ and $5 \mathrm{U}$ of Taq polymerase in a total volume of $50 \mu \mathrm{l}$, and fused. The following conditions were used for fusion: $4.5 \mathrm{~min}$ at $94^{\circ} \mathrm{C}$ for 1 cycle; followed by $30 \mathrm{~s}$ at $94^{\circ} \mathrm{C}, 30 \mathrm{~s}$ at $65^{\circ} \mathrm{C}$, and $50 \mathrm{~s}$ at $72^{\circ} \mathrm{C}$ for 20 cycles; finally, $5 \mathrm{~min}$ at $72^{\circ} \mathrm{C}$. The fused DNA was further amplified using M13 (20) and T3. The FLAG epitope, YKDDDDK, was inserted into the CASR between D371 and T372 by subcloning the final PCR product into rHuPCaR4.0 through the NheI and AflII sites (20). The insertion was confirmed by sequencing.

Determination of cell surface expression by immunocytochemistry. Cells on coverslips transfected with FLAG-tagged CASR or the wild-type, untagged CASR were first fixed with $4 \%$ formaldehyde in PBS for $5 \mathrm{~min}$ at room temperature. Endogenous peroxidases were then inhibited by incubating the cells in Dako Peroxidase Blocking Reagent (Dako Corp., Santa Barbara, CA) for $10 \mathrm{~min}$, and the cells were further treated with Dako Protein Block Serum-Free solution (Dako Corp.) for $1 \mathrm{~h}(11,12)$. Cells were then incubated overnight at $4^{\circ} \mathrm{C}$ with anti-FLAG M2 monoclonal antibody (VWR Scientific, Bridgeport, NJ). The final concentration of antibody was $10 \mu \mathrm{g} / \mathrm{ml}$. After washing the cells three times with $0.5 \%$ BSA in PBS, for $20 \mathrm{~min}$ each, a peroxidase-coupled, sheep anti-mouse IgG, diluted 1:100 (Sigma Chemical Co., St. Louis, MO), was added and incubated for $1 \mathrm{~h}$ at room temperature. The cells were then washed with PBS three times, for 20 min each, and stained with the Dako AEC Substrate System (Dako Corp.) for $\sim 5 \mathrm{~min}$. The color reaction was stopped by washing three times with water. The stained coverslips were mounted on slides with AQUA-MOUNT (Lerner Laboratories, Pittsburgh, PA). Photomicrographs were taken with a $\times 63$ objective.

\section{Results}

Serum total and ionized calcium in affected FHH family members. The affected FHH patients had mean $( \pm \mathrm{SD})$ serum total and ionized calcium concentrations of $2.58 \pm 0.09 \mathrm{mM} /$ $10.32 \pm 0.36 \mathrm{mg} / \mathrm{dl}(n=10)$ and $1.33 \pm 0.05 \mathrm{mM} / 5.32 \pm 0.2 \mathrm{mg} / \mathrm{dl}$ $(n=10)$, respectively, which are slightly higher than those of unaffected family members, that is, $2.27 \pm 0.06 \mathrm{mM} / 9.08 \pm 0.24$ $\mathrm{mg} / \mathrm{dl}(n=4)$ and $1.16 \pm 0.06 \mathrm{mM} / 4.64 \pm 0.24 \mathrm{mg} / \mathrm{dl}(n=4)$, respectively, (significant differences: $P<0.0001$, total calcium; $P<0.0002$, ionized calcium).

Use of a modified PTT to assess the consequence of the Alu insertion. Fig. 2 shows a schematic diagram of the assay indicating the possible RNA and protein products and their predicted sizes. In vitro transcription revealed that the wild-type receptor cDNA yielded a single transcript of $1.5 \mathrm{~kb}$, whereas

\section{IN VITRO TRANSCRIPTION /TRANSLATION}
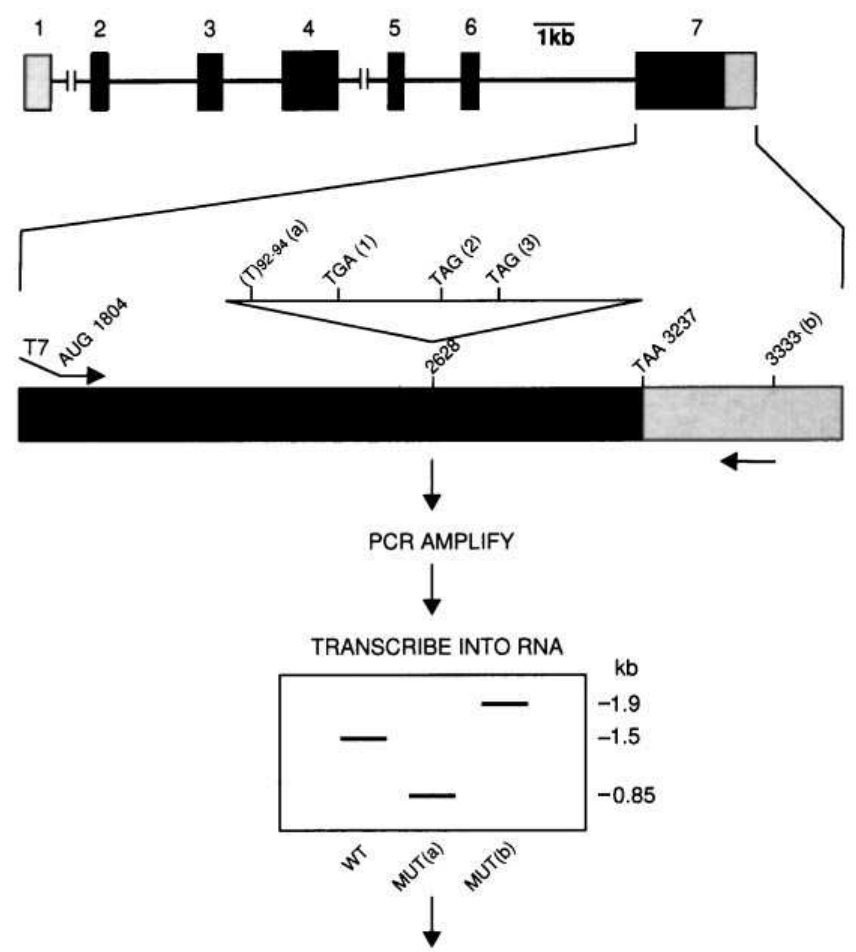

TRANSLATE INTO PROTEIN

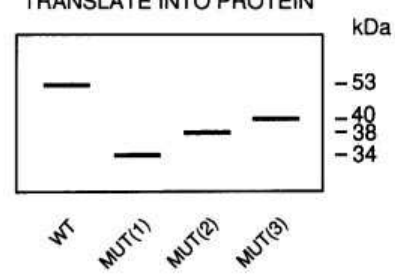

Figure 2. Schematic diagram of protein truncation test used to assess the effects of the Alu insertion on in vitro transcription and translation of a fragment of the CASR consisting of the transmembrane domain and the cytoplasmic tail. 


\section{A) TRANSCRIPTION}

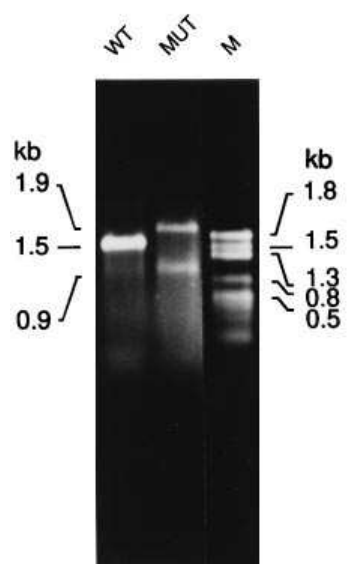

B) TRANSLATION

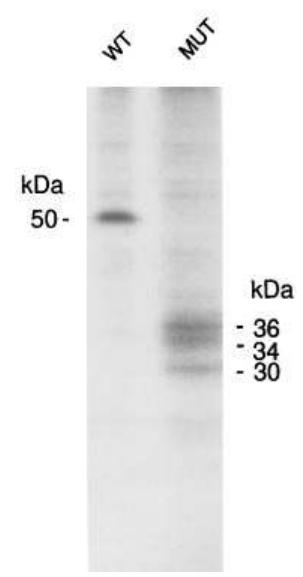

Figure 3. (A) In vitro transcribed products were denatured and electrophoresed in a formaldehyde gel with 0.1 M MOPS (pH 7.0) running buffer. Equal concentrations were loaded in both WT (wildtype) and MUT (mutant) lanes. (B) In vitro translated products obtained in a rabbit reticulocyte system using equal amounts of WT or MUT RNA and $\left[{ }^{3} \mathrm{H}\right]$ leucine were separated by SDS-PAGE (12.5\% polyacrylamide).

the mutant yielded 1.9 and $0.9 \mathrm{~kb}$ products present in approximately equal amounts (Fig. $3 A$ ). Subsequent in vitro translation then gave a single product for wild-type with a molecular mass of $50 \mathrm{kD}$, close to that predicted on the basis of the nucleotide sequence $(53 \mathrm{kD})$, while in vitro translation of the mutant gave rise to three products with molecular weights of 36 , 34 , and $30 \mathrm{kD}$ (Fig. $3 \mathrm{~B}$ ). These are all $\sim 4 \mathrm{kD}$ less than the three predicted species of 910, 946, and 961 amino acids (see Fig. 1). However, the anomalous migration of proteins with unusual amino acid compositions on polyacrylamide gels is well known $(34,35)$, and the observed result is consistent with the presence of the long hydrophobic/polyphenylalanine tract in all three mutant products. Similar results were obtained either by directly analyzing PCR-amplified genomic DNA or after subcloning the DNA. Deletion of the long $(\mathrm{A} / \mathrm{T})$ tract from the Alu mutant led to the elimination of the smaller, arrested transcript, but translation of the poly $(\mathrm{A} / \mathrm{T})$ deleted mutant still yielded three protein products (data not shown).

Western analysis of the CASR containing the Alu insertion mutation. The expressed receptor containing the Alu insertion, like the wild-type receptor, showed three immunoreactive bands, but the sizes of these bands for the mutant receptor were substantially reduced compared to those for the wild-type CASR (Fig. 4). Even the high molecular mass species observed for the wild-type receptor $(\sim 350 \mathrm{kD})$ were also reduced in size. The estimated molecular mass of the nonglycosylated form(s) of the mutated receptor was $\sim 90 \mathrm{kD}$ (range $85-91 \mathrm{kD}), \sim 30 \mathrm{kD}$ smaller than that of the wild-type receptor $(\sim 120 \mathrm{kD})(20)$.

Effect of inhibition of glycosylation of the mutant CASR with tunicamycin. Crude plasma membranes were isolated from HEK293 cells transiently transfected with the mutant CASR and incubated in the presence or absence (control) of tunicamycin for $48 \mathrm{~h}$. The doublet between 140 and $97 \mathrm{kD}$ present in untreated cells was completely absent in cells

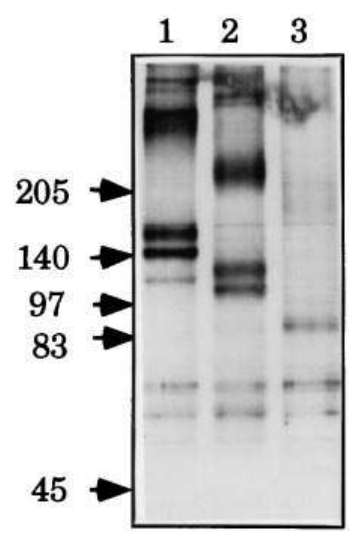

Figure 4. Western analysis of wildtype and mutant receptors. Crude plasma membrane proteins were isolated from HEK293 cells (grown in 100-mm petri dishes) which were transiently transfected with $15 \mu \mathrm{g}$ of the full-length wild-type or mutant receptor cDNAs. The crude plasma membrane protein samples, $4 \mu \mathrm{g}$ each, were subjected to SDS-PAGE on a linear gradient running gel of 4-12\%. (Lane 1) wild-type receptor; (lane 2) mutant receptor with the Alu insertion; (lane 3) mutant receptor isolated from HEK293 cells which had been transiently transfected with the mutant receptor cDNA in the presence of tunicamycin as described in Methods. The CASR proteins were stained with antireceptor antibody, 4641.

treated with tunicamycin and was replaced by a series of bands at $\sim 90 \mathrm{kD}$ (range $86-91 \mathrm{kD}$ ), which is present in the untreated cells but at a much lower level (Fig. 4).

$\mathrm{Ca}^{2+}{ }_{i}$ responses of $\mathrm{HEK} 293$ cells transiently transfected with the CASR CDNA containing the Alu insertion or the CASR (A877 stop) mutant. The wild-type CASR cDNA when transiently expressed in HEK293 cells showed an $\mathrm{EC}_{50}$ value for

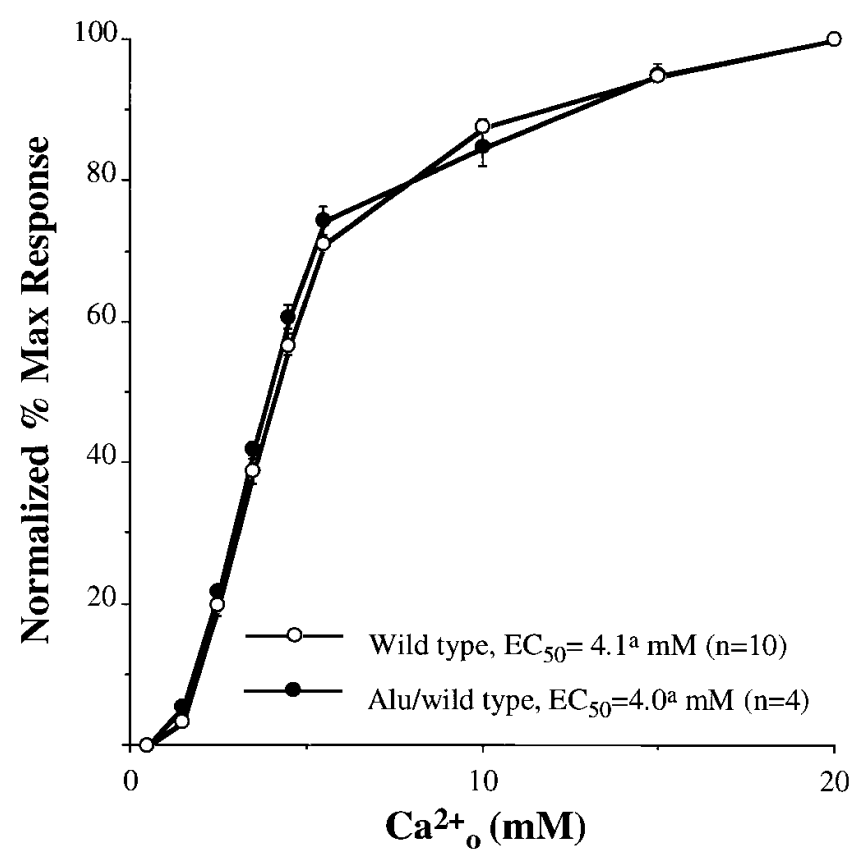

Figure 5. High $\mathrm{Ca}^{2+}{ }_{\mathrm{o}}$-evoked increases in $\mathrm{Ca}^{2+}{ }_{\mathrm{i}}$ in fura-2-loaded HEK293 cells transiently transfected with the wild-type receptor alone or cotransfected with the wild-type and mutant receptors (see text for details). Each data point is the mean value of four measurements. The responses are normalized to the maximum responses of the wild-type receptor. The SEM is indicated with a vertical bar through each point. The effective concentration $\left(\mathrm{EC}_{50}\right)$ for each curve is presented as mean $\pm \mathrm{SEM}$. The mean $\mathrm{EC}_{50}$ 's for the wild-type receptor alone and the cotransfected wild-type and mutant receptors were not significantly $(P>0.05)$ different. In this experiment, $0.625 \mu \mathrm{g}$ of each cDNA was used to transfect HEK293 cells plated on a rectangular coverslip (within individual wells of 12-well plates). 


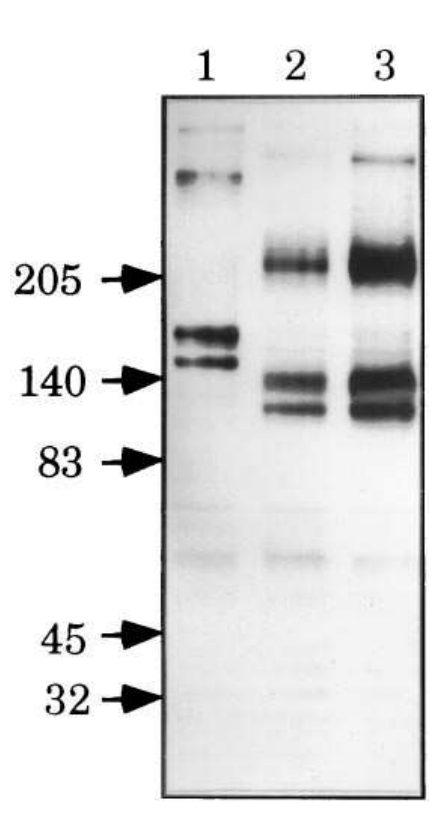

Figure 6. Western analysis of wild-type and mutant CASR. Crude plasma membrane proteins were isolated from HEK293 cells (grown in 100-mm petri dishes) that were transiently transfected with $3.75 \mu \mathrm{g}$ of the wild-type rHuPCaR4.0, the mutant receptor with Alu insertion or the truncated receptor (A877stop). The crude plasma membrane protein samples, $4 \mu \mathrm{g}$ each, were subjected to SDS-PAGE on a linear gradient running gel of $4-12 \%$. (Lane 1) rHuPCaR4.0; (lane 2) the mutant receptor with Alu insertion; (lane 3) A877stop. The CASR proteins were stained with antireceptor antibody, 4641 , as described in Methods.

$\mathrm{Ca}^{2+}{ }_{0}$ of $4.2 \pm 0.2 \mathrm{mM}$ (mean \pm SEM) (Fig. 5), but the mutant Alu insertion and (A877stop) receptors hardly responded at all to $\mathrm{Ca}^{2+}{ }_{\mathrm{o}}$ at $50 \mathrm{mM}(<10 \%$ of the response of the wild-type receptor) (data not shown) and did not respond to $\mathrm{Gd}^{3+}{ }_{\mathrm{o}}$ at levels as high as $500 \mu \mathrm{M}$ (data not shown).

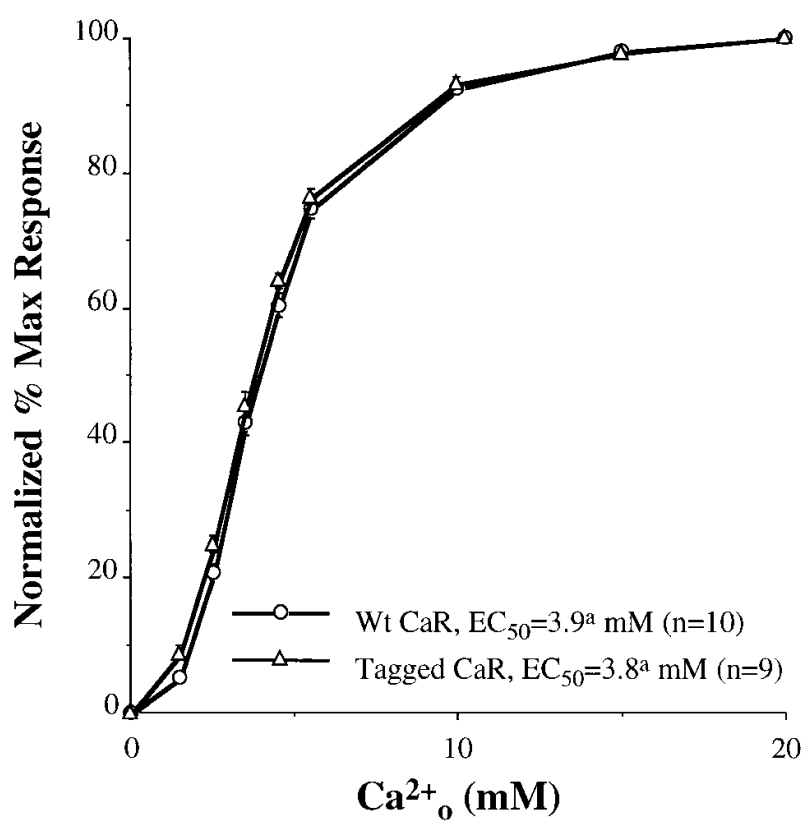

Figure 7. High $\mathrm{Ca}^{2+}{ }_{\mathrm{o}}$-evoked increases in $\mathrm{Ca}^{2+}{ }_{\mathrm{i}}$ in fura-2-loaded HEK293 cells transiently transfected with the wild-type rHuPCaR4.0 or FLAG-tagged rHuPCaR4.0 (see text for details). Each data point is the mean value of 9-10 measurements. The responses are normalized to the maximum response of the wild-type receptor (rHuPCaR4.0). The SEM is indicated with a vertical bar through each point. The $\mathrm{EC}_{50}$ for each curve is presented as mean $\pm \mathrm{SEM}$. The mean $\mathrm{EC}_{50}$ 's for the wild-type receptor and the FLAG-tagged wildtype receptor were not significantly $(P>0.05)$ different. In this experiment, $0.625 \mu \mathrm{g}$ of each cDNA was used to transfect HEK293 cells plated on a rectangular coverslip (within individual wells of 12-well plates).
Coexpression of the wild-type receptor with the Alu insertion mutant receptor. The mutant receptor did not interfere with the function of the coexpressed wild-type receptor (Fig. 5). The $\mathrm{Ca}^{2+}{ }_{0}$ dose-response curve of the coexpressed receptors was essentially superimposable on that of the wild-type receptor alone.

Western analysis of the CASR containing the Alu insertion mutation and a truncated mutant CASR (A877 stop). Although the mutant receptor with the Alu insertion is predicted to have at least 34 amino acids unrelated to CASR protein after T876 (the position of the Alu insertion), the mutant has an apparent molecular mass on SDS-PAGE similar to the receptor truncated after T876 (Fig. 6). A similar anomolous migration on SDSPAGE was noted above for protein fragments obtained from in vitro translation of Alu-containing PCR products which had estimated sizes smaller than their predicted molecular masses (see Fig. 3). This is most probably due to the polyphenylalanine tract encoded by the long poly (A/T) sequence of the Alu insertion. Interestingly, the expression level of the truncated mutant at A877 is substantially higher than that of the wildtype receptor.

Characterization of FLAG-tagged wild-type receptor. To facilitate immunocytochemical analysis of wild-type and mutant receptors on the cell surface, we created a CASR containing the FLAG epitope within the extracellular domain (see Methods). The FLAG-tagged wild-type receptor is similar to the wild-type nontagged receptor in terms of its $\mathrm{Ca}^{2+}{ }_{i}$ response to $\mathrm{Ca}^{2+}{ }_{\mathrm{o}}$ (Fig. 7), and the levels of protein expression for the two receptors determined by Western analysis of crude membrane preparations and staining with antireceptor antibody,

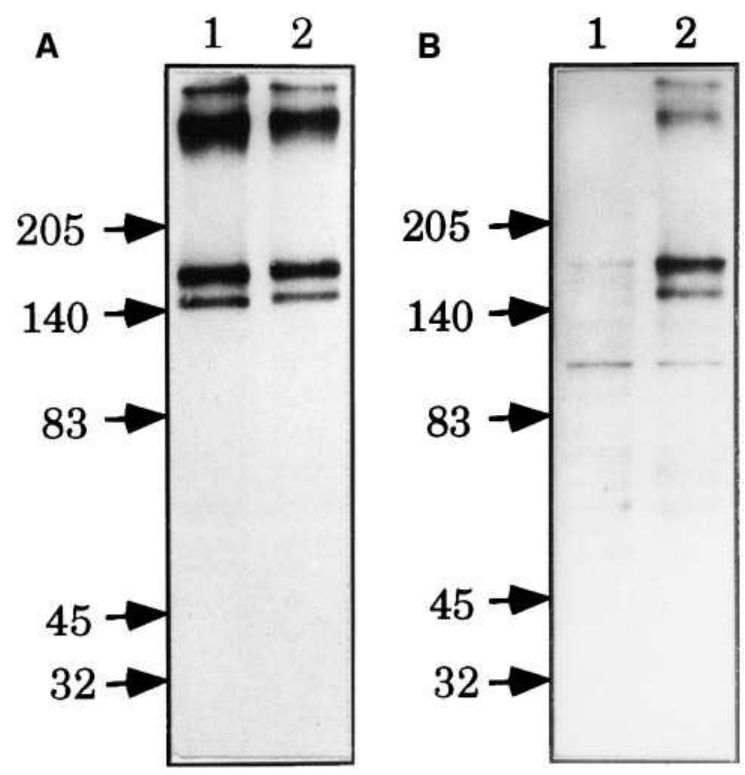

Figure 8. Western analysis of the FLAG-tagged rHuPCaR4.0. Crude plasma membrane proteins were isolated from HEK293 cells (grown in 100-mm petri dishes) which were transiently transfected with 3.75 $\mu \mathrm{g}$ of the wild-type rHuPCaR4.0 or FLAG-tagged rHuPCaR4.0. The crude plasma membrane protein samples, $4 \mu \mathrm{g}$ each, were subjected to SDS-PAGE on a linear gradient running gel of 4-12\%. In both $A$ and $B$, lane 1: rHuPCaR4.0; lane 2: FLAG-tagged rHuPCaR4.0. In $A$, the CASR proteins were stained with antireceptor antibody, 4641, as described in Methods. In $B$, the FLAG-tagged rHuPCaR4.0 was stained with anti-FLAG M2 monoclonal antibody. 

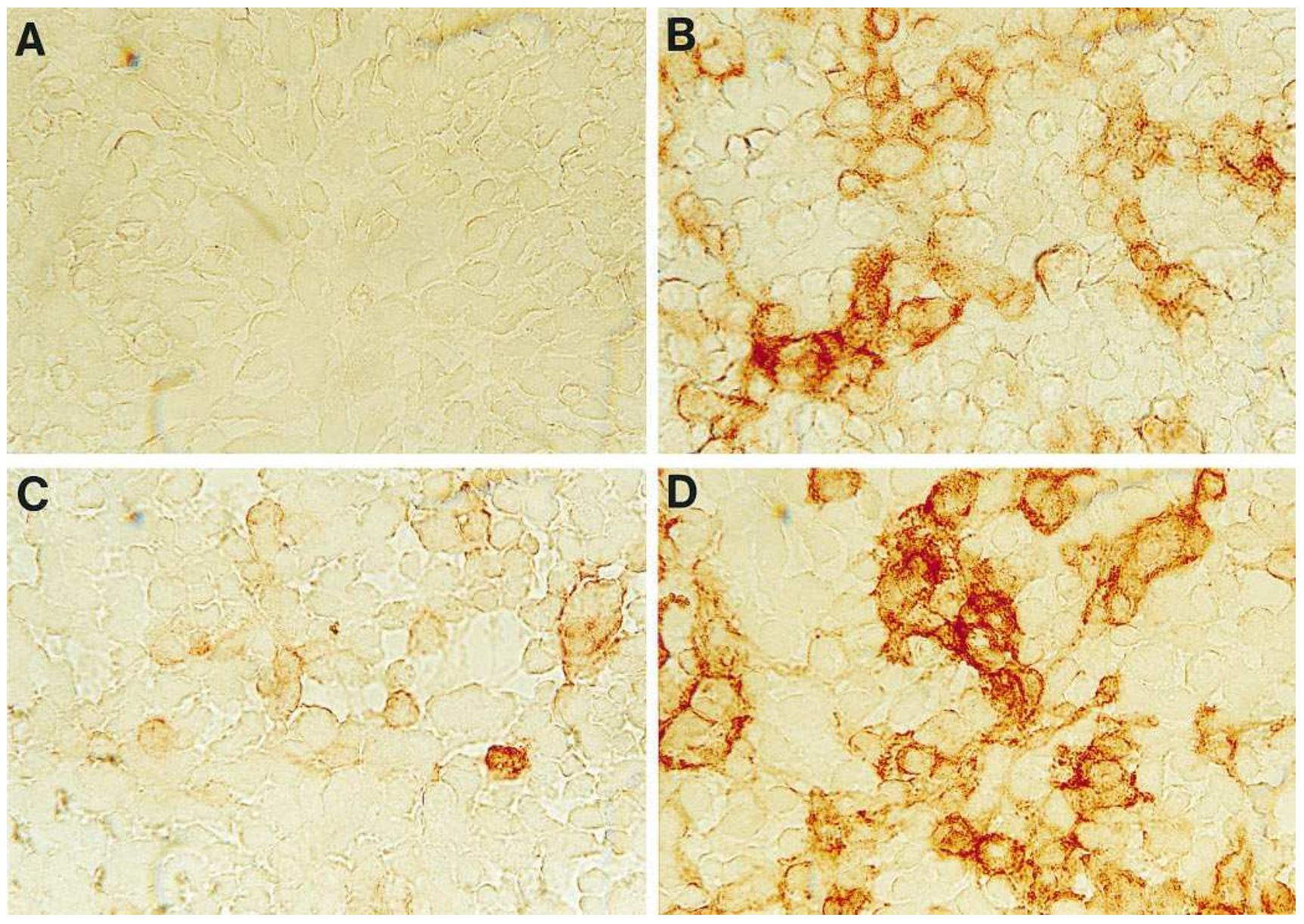

Figure 9. Immunocytochemical detection of CASR proteins on the surface of HEK293 cells transiently transfected with FLAG-tagged receptors. The cells were plated on circular coverslips (within individual wells of 24-well plates) and transfected with $0.313 \mu \mathrm{g}$ of the receptor cDNAs as described in Methods. The transfected cells were fixed with $4 \%$ formaldehyde and immunostained with anti-FLAG M2 monoclonal antibody. $(A)$ rHuPCaR4.0 without the FLAG tag; $(B)$ FLAG-tagged rHuPCaR4.0; $(C)$ FLAG-tagged mutant receptor with the Alu insertion; $(D)$ FLAG-tagged A877stop.

4641 (Fig. $8 A$ ) are also similar. The specificity of staining with the anti-FLAG M2 monoclonal antibody is demonstrated in Fig. 8 B.

Determination of cell surface expression of the FLAGtagged receptors using immunocytochemistry. As shown in Fig. 9 B, HEK293 cells transfected with the FLAG-tagged wild-type receptor have strong staining with anti-FLAG M2 monoclonal antibody which is not present in cells transfected with the wild-type receptor without the tag (Fig. 9A). The rimlike staining of the cells expressing the wild-type receptor is characteristic of the cell surface expression of the receptor. Such staining is much reduced in the cells transfected with the mutant receptor with the Alu insertion (Fig. 9 C). In contrast, cells transfected with the truncated mutant receptor (A877 stop) (Fig. $9 D$ ) have much more pronounced rim-like staining than that of the wild-type receptor consistent with its higher level of expression as assessed by Western analysis (Fig. 6).

\section{Discussion}

Alu-repetitive elements are detected predominantly within introns or the $5^{\prime}$ - and $3^{\prime}$-noncoding regions of genes. The presence of an Alu sequence in a coding region is an extremely rare event $(36,37)$ and the functional consequences of such an insertion have not been studied previously. The Alu-repetitive element in the FHH kindreds studied here is in the opposite orientation to the $C A S R$ gene and contains an exceptionally long $\operatorname{poly}(\mathrm{A} / \mathrm{T})$ tract. The mutated receptor is predicted to have the $\mathrm{NH}_{2}$-terminal wild-type sequence up to amino acid 876 and to be terminated at a stop codon positioned after a stretch of unrelated sequence, Gln-Leu-Thr-Leu-Ser and 29 phenylalanines, all of which are derived from the Alu insertion. In vitro transcription and translation of the mutant receptor gene resulted in three protein products corresponding to termination of translation after amino acids 910, 946, and 961 as predicted (see Fig. 1). This finding most likely relates to the expansion and contraction during transcription of the length of the polyuridine tracts encoded by this Alu sequence. Poly(A/T) tracts are well known to encourage frameshift mutagenesis and slippage during replication by DNA polymerases (38) and transcription by RNA polymerases (39). With reference to DNA replication it has been documented previously that the poly $(\mathrm{A} / \mathrm{T})$ tracts of Alu sequences are polymorphic (40-42). There are two stretches of $\operatorname{poly}(\mathrm{A} / \mathrm{T})$ within the Alu repeat of the $C A S R$. One corresponds to the extremely long poly(A) tail and the other to the A-rich region typically found between the 
right and left monomers (43). When we deleted the long poly (A/T) tract, slippage during transcription/translation was still apparent indicating that other sequences, probably the shorter A/T-rich region, were also contributing to the frame-shift mutagenesis. It has been hypothesized (44) that antisense Alu elements found within exons are not translated, because of their complementarity to 7SL RNA, a component of the signal recognition particle. It was speculated that the RNA would hybridize with the antisense Alu sequence, thereby inhibiting the elongation process. Our data is inconsistent with this hypothesis and demonstrates that the Alu-directed frameshift mutagenesis affected the process of mRNA translation in a qualitative manner leading to the production of three related mutant proteins differing only in their $\mathrm{COOH}$-terminal tails. Importantly, it is likely this was occurring not only in the in vitro PTT assay, but also in the HEK293 cells transfected with the Alu mutant construct, in which closely sized proteins, ranging from 86-91 $\mathrm{kD}$, were apparent on Western analysis using the CASR antibody in the crude plasma membrane preparation (see Fig. 4, lane 3). A transcriptional effect of the Alu was also apparent in vitro, and we noted the generation of a shorter transcript representing up to $50 \%$ of the full-length mutant transcript. The size of the shorter transcript was consistent with truncation occurring just at the beginning of the long poly $(\mathrm{A} / \mathrm{T})$ tract, a known "arrest site" for RNA polymerases $(45,46)$. In addition, deletion of the $\operatorname{poly}(\mathrm{A} / \mathrm{T})$ tract abolished the generation of the shorter transcript.

The mutant receptor shows a qualitatively similar expression pattern and levels of the corresponding receptor species by Western analysis were similar to those of wild-type receptor albeit with proportionally reduced sizes. Thus, the insertion does not interfere with the stability of the truncated receptor protein that was translated from the mRNA harboring it. Therefore, the Alu insertion may cause inactivation of the receptor by impairing its signal transduction capabilities, as we also demonstrated with a mutant CASR truncated at the site of the Alu insertion, through loss of the majority of its $\mathrm{COOH}$ terminal intracellular domain which can be important for $\mathrm{G}$ protein coupling (47). Also, much reduced cell-surface expression of the mutant receptor was demonstrated indicating a further deleterious effect of the additional missense sequence in retarding the trafficking of the mutant receptor to the cell surface. In contrast, the overall expression of the CASR (A877 stop) mutant was markedly increased relative to that of wildtype CASR, and this was reflected in its greater cell surface expression. At present little is known of the potential for desensitization of the CASR which may occur in a similar fashion to that shown for other $G$ protein-coupled receptors. This occurs by rapid uncoupling of the receptor from its $G$ protein(s), subsequent sequestration of the receptor from the plasma membrane, and internalization followed by proteolytic degradation (48). Our data points to a potentially important role of the $\mathrm{COOH}$-terminal domain in mediating the normal internalization and degradation of the CASR.

The mutant Alu insertion receptor also did not interfere with the normal function of the coexpressed wild-type receptor in HEK293 cells, in agreement with the observation that heterozygotes (i.e., with $\mathrm{FHH}$ ) with one mutated and one normal allele in these three kindreds have very mild elevations in serum calcium $(2.58 \mathrm{mM})$ versus unaffected individuals $(2.27 \mathrm{mM})$. This is analogous to the situation in an animal model in which mice heterozygous for targeted disruption of the CASR gene manifest only a slight increase in serum calcium concentration (49). This emphasizes the important role of gene dosage in determining the level of CASR protein on the parathyroid cell surface. In contrast, individuals homozygous for the Alu insertion mutation (i.e., with NSHPT) have very severe elevations of both serum calcium as well as PTH $(13,23)$ due to the total absence of functional CASRs.

In summary, we report a functional analysis of a naturally occurring mutation that deletes much of the COOH-terminal region of the CASR. Further structure-function studies of this region of the CASR will lead to a more precise understanding of the requirements for receptor/G protein-coupling and desensitization of the receptor. In addition, our studies provide novel insights into the way in which insertion of a repetitive element into a protein-coding exon can disrupt gene expression.

\section{Acknowledgments}

We thank Drs. J.E. Garrett, I.V. Capuano, A. Paruhar, F. Fuller, R.T. Simin, and K.V. Rogers for providing us with the pHuPCaR4.0 plasmid, HEK293 cells, as well as anti-CASR antibody, 4641, and its blocking peptide. We thank Dr. Karen Meerovitch and Ms. Lucie Canaff for help with the transcription/translation assay and Ms. Pamela Kirk for preparation of the manuscript.

Support for this work was provided by the National Institutes of Health (grants DK09436, DK44588, DK41415, 48830, HL42120 and DK40127), The St. Giles Foundation, NPS Pharmaceuticals, Inc., the Medical Research Council of Canada (grant MT-9315) and the Canadian Kidney Foundation. N. Janicic is the recipient of Studentships from the Cancer Research Society and the Fonds de la recherche en santé du Québec, and G.N. Hendy is a Scientist of the Medical Research Council of Canada.

\section{References}

1. Foley, T.P., Jr., H.C. Harrison, C.D. Arnaud, and H.E. Harrison. 1972. Familial benign hypercalcemia. J. Pediatr. 81:1060-1067.

2. Marx, S.J., M.F. Attie, M.A. Levine, A.M. Spiegel, R.W. Downs, Jr., and R.D. Lasker. 1981. The hypocalciuric or benign variant of familial hypercalcemia: clinical and biochemical features in fifteen kindreds. Medicine (Baltimore). 60:397-412.

3. Law, W., and H. Heath III. 1985. Familial benign hypercalcemia (hypocalciuric hypercalcemia): clinical and pathogenic studies in 21 families. Ann. Intern. Med. 102:511-519.

4. Pratt, E.L., B.B. Beren, and E.B.D. Neuhauser. 1947. Hypercalcaemia and idiopathic hyperplasia of the parathyroid glands in an infant. J. Pediatr. 30: 388-399.

5. Goldbloom, R.B., D.A. Gillis, and M. Prasad. 1972. Hereditary parathyroid hyperplasia: a surgical emergency of early infancy. Pediatrics. 49:514-523.

6. Steinmann, B., H.E. Gnehm, V.H. Rao, H.P. Kind, and A. Prader. 1984 Neonatal severe primary hyperparathyroidism and alkaptonuria in a boy born to related parents with familial hypocalciuric hypercalcemia. Helv. Paediatr. Acta. 39:171-186.

7. Marx, S.J., M.F. Attie, A.M. Spiegel, M.A. Levine, R.D. Lasker, and M. Fok. 1982. An association between neonatal severe primary hyperparathyroidism and familial hypocalciuric hypercalcemia in three kindreds. N. Engl. J. Med. 306:257-264.

8. Marx, S.J., D. Fraser, and A. Rapoport. 1985. Familial hypocalciuric hypercalcemia. Mild expression of the gene in heterozygotes and severe expression in homozygotes. Am. J. Med. 78:15-22.

9. Brown, E.M., G. Gamba, D. Riccardi, M. Lombardi, R. Butters, O. Kifor, A. Sun, M.A. Hediger, J. Lytton, and S.C. Herbert. 1993. Cloning, expression, and characterization of an extracellular $\mathrm{Ca}^{2+}$ sensing receptor from bovine parathyroid. 1993. Nature (Lond.). 366:575-580.

10. Garrett, J.E., I.V. Capuano, L.G. Hammerland, B.C.P. Hung, E.M Brown, S.C. Hebert, E.F. Nemeth, and F. Fuller. 1995. Molecular cloning and functional expression of human parathyroid calcium receptor cDNAs. J. Biol. Chem. 270:12919-12925.

11. Janicic, N., E. Soliman, Z. Pausova, M.F. Seldin, M. Rivière, J. Szpirer, C. Szpirer, and G.N. Hendy. 1995. Mapping of the calcium-sensing receptor gene (CASR) to human chromosome 3q13.3-21 by fluorescence in situ hybridization, and localization to rat chromosome 11 and mouse chromosome 16 . 
Mamm. Genome. 6:798-801.

12. Pollak, M.R., E.M. Brown, Y-H.W. Chou, S.C. Hebert, S.J. Marx, B. Steinmann, T. Levi, C.E. Seidman, and J.G. Seidman. 1993. Mutations in the human $\mathrm{Ca}^{2+}$-sensing receptor gene cause familial hypocalciuric hypercalcemia and neonatal severe hyperparathyroidism. Cell. 75:1297-1303.

13. Pollak, M.R., Y-H.W. Chou, S.J. Marx, B. Steinmann, D.E.C. Cole, M.L. Brandi, S.E. Papapoulos, F.H. Menko, G.N. Hendy, E.M. Brown, et al. 1994. Familial hypocalciuric hypercalcemia and neonatal severe hyperparathyroidism: the effects of mutant gene dosage on phenotype. J. Clin. Invest. 93: 1108-1112.

14. Chou, Y-H.W., M.R. Pollak, M.L. Brandi, G. Toss, H. Arnqvist, A.B. Atkinson, S.E. Papapoulos, S. Marx, E.M. Brown, J.G. Seidman, and C.E. Seidman. 1995. Mutations in the human $\mathrm{Ca}^{2+}$-sensing-receptor gene that cause familial hypocalciuric hypercalcemia. Am. J. Hum. Genet. 56:1075-1079.

15. Pearce, S.H.S., D. Trump, C. Wooding, G.M. Besser, S.L. Chew, D.B. Grant, D.A. Heath, I.A. Hughes, C.R. Peterson, M.P. Whyte, and R.V. Thakker. 1995. Calcium-sensing receptor mutations in familial benign hypercalcemia and neonatal hyperparathyroidism. J. Clin. Invest. 96:2683-2692.

16. Heath, H. III, S. Odelberg, C.E. Jackson, B.T. The, N. Hayward, C. Larsson, N.R.M. Buist, K.J. Krapcho, B.C. Hung, I.V. Capuano, et al. 1996. Clustered inactivating and benign polymorphisms of the calcium receptor gene in familial benign hypocalciuric hypercalcemia suggest receptor functional domains. J. Clin. Endocrinol. \& Metab. 81:1312-1317.

17. Janicic, N., Z. Pausova, D.E.C. Cole, and G.N. Hendy. 1995b. Insertion of an Alu sequence in the $\mathrm{Ca}^{2+}$-sensing receptor gene in familial hypocalciuric hypercalcemia (FHH) and neonatal severe hyperparathyroidism (NSHPT). Am. J. Hum. Genet. 56:880-886.

18. Brown, E.M. 1991. Extracellular $\mathrm{Ca}^{2+}$ sensing, regulation of parathyroid cell function, and role of $\mathrm{Ca}^{2+}$ and other ions as extracellular (first) messengers. Physiol. Rev. 71:371-411.

19. Chattopadhyay, N., A. Mithal, and E.M. Brown. 1996. The calciumsensing receptor: a window into the physiology and pathophysiology of mineral ion metabolism. Endocr. Rev. 17:289-307.

20. Bai, M., S. Quinn, S. Trivedi, O. Kifor, S.H.S. Pearce, M. Pollak, K. Krapcho, and E.M. Brown. 1996. Expression and characterization of inactivating and activating mutations in the human $\mathrm{Ca}^{2+}{ }_{0}$-sensing receptor. J. Biol. Chem. 271:19537-19545.

21. Pearce, S.H.S., M. Bai, S.J. Quinn, O. Kifor, E.M. Brown, and R.V. Thakker. 1996. Functional characterization of calcium-sensing receptor mutations expressed in human embryonic kidney cells. J. Clin. Invest. 98:1860-1866.

22. Marx, S.J., R.D. Lasker, E.M. Brown, L.A. Fitzpatrick, N.B. Sweezey, R.B. Goldbloom, D.A. Gillis, and D.E.C. Cole. 1986. Secretory dysfunction in parathyroid cells from a neonate with severe primary hyperparathyroidism. $J$. Clin. Endocrinol. \& Metab. 62:445-449.

23. Cole, D.E.C., C.R. Forsyth, J.M. Dooley, E.B. Grantmyre, and S.R. Salisbury. 1990. Primary neonatal hyperparathyroidism: a devastating neurodevelopmental disorder if left untreated. J. Craniofacial Genet. Dev. Biol. 10:205-214.

24. Ausabel, F.M., R. Brent, R.E. Kingston, D.D. Moore, J.G. Seidman, J.A. Smith, and K. Struhl, editors. 1987. Current Protocols in Molecular Biology. John Wiley \& Sons, New York.

25. Melton, D.A., P.A. Krieg, M.R. Rebagliati, T. Maniatis, K. Zinn, and M.R. Green. 1984. Efficient in vitro synthesis of biologically active RNA and RNA hybridization probes from plasmids containing a bacteriophage SP6 promoter. Nucleic Acids Res. 12:7035-7056.

26. Kunkel, T.A. 1985. Rapid and efficient site-specific mutagenesis without phenotypic selection. Proc. Natl. Acad. Sci. USA. 82:488-492.

27. Hawley-Nelson, P., V. Ciccarone, G. Gebeyehu, J. Jessee, and P.L. Felgner. 1993. Focus. 15:73-79.

28. Duksin, D., M. Seiberg, and W.C. Mahoney. 1982. Inhibition of protein glycosylation and selective cytotoxicity toward virally transformed fibroblasts caused by B3-Tunicamycin. Eur. J. Biochem. 129:77-80.

29. Sun, G.Y., H.-M. Huang, J.A. Kelleher, E.B. Stubbs, Jr., and A.Y. Sun. 1988. Marker enzymes, phospholipids and acyl group composition and a somal plasma membrane fraction isolated from rat cerebral cortex: a comparison with microsomes and synaptic plasma membranes. Neurochem. Int. 12:69-77.

30. Laemmli, U.K. 1970. Cleavage of structural proteins during the assembly of the head of bacteriophage T4. Nature (Lond.). 227:680-685.

31. Fajtova, V.T., S.J. Quinn, and E.M. Brown. 1991. Cytosolic calcium responses of single rMTC 44-2 cells to stimulation with external calcium and potassium. Am. J. Physiol. 261:E151-E158.

32. Duncan, D.B. 1955. Multiple range and multiple F tests. Biometrics. 11: $1-42$.

33. Snedecor, G.W., and W.G. Cochran. 1967. Statistical Methods. 6th Ed. Iowa State Univ. Press. Ames, IA.

34. Weber, K., J.R. Pringle, and M. Osborn. 1972. Measurement of molecular weights by electrophoresis on SDS-acrylamide gel. Methods Enzymol. 26:3-27.

35. Hope, I.A., and K. Struhl. 1985. GCN4 protein synthesized in vitro, binds HIS3 regulatory sequences: implications for general control of amino acid biosynthetic genes in yeast. Cell. 43:177-188.

36. Makalowski, W., G.A. Mitchell, and D. Labuda. 1994. Alu sequences in the coding regions of mRNA: a source of protein variability. Trends Genet. 10: $188-193$.

37. Labuda, D., E. Zietkiewicz, and G.A. Mitchell. 1995. Alu elements as a source of genomic variation: deleterious effects and evolutionary novelties. In The impact of short interspersed elements (SINES) on the host genome. R.J. Maraia, editor. R.G. Landes Co. 1-24.

38. Kunkel, T.A. 1986. Frameshift mutagenesis by eukaryotic DNA polymerases in vitro. J. Biol. Chem. 261:13581-13587.

39. Macdonald, L.E., Y. Zhou, and W.T. McAllister. 1993. Termination and slippage by bacteriophage T7 RNA polymerase. J. Mol. Biol. 232:1030-1047.

40. Economou, E.P., A.W. Bergen, A.C. Warren, and S.E. Antonarakis. 1990. The polydeoxyadenylate tract of Alu repetitive elements is polymorphic in the human genome. Proc. Natl. Acad. Sci. USA. 87:2951-2954.

41. Epstein, N., O. Nahor, and J. Silver. 1990. The 3' ends of alu repeats are highly polymorphic. Nucleic Acids Res. 18:4634.

42. Zuliani, G., and H.H. Hobbs. 1990. A high frequency of length polymorphism in repeated sequences adjacent to Alu sequences. Am. J. Hum. Genet. 46: 963-969.

43. Deininger, P.L. 1989. SINEs: short interspersed repeated DNA elements in higher eucaryotes. In Mobile DNA. D.E. Berg, M.M. Howe, editors. American Society for Microbiology, Washington, DC. 619-636.

44. Brownell, E., N. Mittereder and N. Rice. 1989. A human rel proto-oncogene cDNA containing an Alu fragment as a potential coding exon. Oncogene. 4:935-942.

45. Resnekov, O., and Y. Aloni. 1989. RNA polymerase II is capable of pausing and prematurely terminating transcription at a precise location in vivo and in vitro. Proc. Natl. Acad. Sci. USA. 86:12-16.

46. Kerppola, T.K., and C.M. Kane. 1990. Analysis of the signals for transcription termination by purified RNA polymerase II. Biochemistry. 29:269-278.

47. Chang, W., S. Pratt, T.-H. Chen, and D.M. Shoback. 1996. Signal transduction properties of carboxyterminal truncation mutants of the parathyroid calcium-sensing receptor. Program \& Abstracts 10th International Congress of Endocrinology. OR54-1.725.

48. Dohlman, H.G., J. Thorner, M.G. Caron, and R.J. Lefkowitz. 1991. Model systems for the study of seven-transmembrane-segment receptors. Annu. Rev. Biochem. 60:653-688.

49. Ho, C., D.A. Conner, M.R. Pollack, D.J. Ladd, O. Kifor, H.B. Warren, E.M. Brown, J.G. Seidman, and C.E. Seidman. 1995. A mouse model of human familial hypocalciuric hypercalcemia and neonatal severe hyperparathyroidism. Nature Genet. 11:389-394. 